\title{
ADC
}

\section{Mitochondrial encephalocardio-myopathy with early neonatal onset due to TMEM70 mutation}

Tomás Honzík, Markéta Tesarová, Johannes A Mayr, et al.

Arch Dis Child 2010 95: 296-301

doi: 10.1136/adc.2009.168096

Updated information and services can be found at:

http://adc.bmj.com/content/95/4/296.full.html

\section{These include:}

References This article cites 33 articles, 12 of which can be accessed free at: http://adc.bmj.com/content/95/4/296.full.html\#ref-list-1

Email alerting Receive free email alerts when new articles cite this article. Sign up in the service box at the top right corner of the online article.

Notes

To order reprints of this article go to:

http://adc.bmj.com/cgi/reprintform

To subscribe to Archives of Disease in Childhood go to:

http://adc.bmj.com/subscriptions 


\title{
Mitochondrial encephalocardio-myopathy with early neonatal onset due to TMEM70 mutation
}

\author{
Tomáš Honzík, Markéta Tesařová,, Johannes A Mayr, ${ }^{2}$ Hana Hansíková, ${ }^{1}$ Pavel Ješina, \\ Olaf Bodamer, ${ }^{2}$ Johannes Koch, ${ }^{2}$ Martin Magner, ${ }^{1}$ Peter Freisinger, ${ }^{3}$ Martina Huemer, ${ }^{4}$ \\ Olga Kostková, ${ }^{1}$ Rudy van Coster, ${ }^{5}$ Stanislav Kmoch, ${ }^{6}$ Josef Houštêk, ${ }^{7}$ Wolfgang Sperl, ${ }^{2}$ \\ Jiř́ Zeman
}

'Department of Pediatrics and Adolescent Medicine, First Faculty of Medicine, Charles University in Prague, Prague, Czech Republic

2Department of Pediatrics, Paracelsus Medical University, Salzburg, Austria

${ }^{3}$ Children's Hospital Schwabing, Technical University Munich,

Munich, Germany

${ }^{4}$ Department of Pediatrics, Landeskrankenhaus Bregenz, Bregenz, Austria

${ }^{5}$ Department of Pediatrics, University Hospital Ghent, Ghent, Belgium

${ }^{6}$ Institute of Inherited Metabolic Disorders, First Faculty of Medicine, Charles University in Prague, Prague, Czech Republic

${ }^{7}$ Department of Bioenergetics, Institute of Physiology, Academy of Science of the Czech Republic, Prague, Czech Republic

\section{Correspondence to}

Professor Ji í Zeman,

Department of Pediatrics and Adolescent Medicine, First

Faculty of Medicine, Charles University in Praque, Ke

Karlovu 2, 12808 Prague 2.

Czech Republic:

jzem@lf1.cuni.cz or Professor

Wolfgang Sperl,

Department of Pediatrics,

Paracelsus Medical University, Müllner Hauptstrasse 48, A-5020 Salzburg, Austria; w.sperl@salk.at

Accepted 21 November 2009

\section{ABSTRACT \\ Objective Mitochondrial disturbances of energy- generating systems in childhood are a heterogeneous group of disorders. The aim of this multi-site survey was to characterise the natural course of a novel mitochondrial disease with ATP synthase deficiency and mutation in the TMEM70 gene.}

Methods Retrospective clinical data and metabolic profiles were collected and evaluated in 25 patients (14 boys, 11 girls) from seven European countries with a c. $317-2 \mathrm{~A} \rightarrow \mathrm{G}$ mutation in the TMEM70 gene.

Results Severe muscular hypotonia (in $92 \%$ of newborns), apnoic spells (92\%), hypertrophic cardiomyopathy (HCMP; 76\%) and profound lactic acidosis (lactate $5-36 \mathrm{mmol} /$; $92 \%$ ) with hyperammonaemia (100-520 $\mathrm{mmol} / \mathrm{l} ; 86 \%)$ were present from birth. Ten patients died within the first 6 weeks of life. Most patients surviving the neonatal period had persisting muscular hypotonia and developed psychomotor delay. HCMP was non-progressive and even disappeared in some children. Hypospadia was present in $54 \%$ of the boys and cryptorchidism in $67 \%$. Increased excretion of lactate and 3-methylglutaconic acid (3-MGC) was observed in all patients. In four surviving patients, life-threatening hyperammonaemia occurred during childhood, triggered by acute gastroenteritis and prolonged fasting.

Conclusions ATP synthase deficiency with mutation in TMEM70 should be considered in the diagnosis and management of critically ill neonates with early neonatal onset of muscular hypotonia, HCMP and hypospadias in boys accompanied by lactic acidosis, hyperammonaemia and 3-MGC-uria. However, phenotype severity may vary significantly. The disease occurs frequently in the Roma population and molecular-genetic analysis of the TMEM70 gene is sufficient for diagnosis without need of muscle biopsy in affected children.

\section{INTRODUCTION}

Mitochondrial diseases are a heterogeneous group of disorders of the oxidative phosphorylation system (OXPHOS) composed of four respiratory chain complexes and $\mathrm{F}_{1} \mathrm{~F}_{0}$-ATP synthase (complex V). OXPHOS, as the only exception in mammalian cells, is under the genetic control of two genomes, nuclear DNA and maternally transmitted mitochondrial DNA (mtDNA). In mitochondrial diseases, tissues with high energy demand such as the brain, muscle and heart, are affected most frequently. Recently, an increasing

\section{What is already known on this topic}

- An increasing number of children with mitochondrial diseases and isolated ATP synthase deficiency have been identified.

- Muscular hypotonia, hypertrophic cardiomyopathy (HCMP) and lactic acidosis are often found in patients with mitochondrial disease.

- A large number of nuclear genes related to OXPHOS have been described whose mutations result in mitochondrial disease.

\section{What this study adds}

- ATP synthase deficiency due to TMEM70 mutation is a novel mitochondrial disease with neonatal onset with hypotonia, HCMP, lactic acidosis, hypospadias, hyperammonaemia and 3-methylglutaconic aciduria.

- The course of the disease was described in a patients with TMEM70 mutation from seven European countries.

- The distinct phenotype enables moleculargenetic diagnosis without the need for a muscle biopsy.

number of nuclear genes have been described that are related to OXPHOS and their mutations result in mitochondrial diseases. ${ }^{1}$ Substantial progress has been also achieved in understanding the molecular basis of severe mitochondrial diseases due to isolated deficiency of ATP synthase, the key enzyme involved in the mitochondrial energy conversion and providing most of the cellular ATP.

Isolated deficiency of ATP synthase may originate from mutations in mtDNA or nuclear genes. The maternally inherited disorders of ATP synthase are caused by mtDNA mutations in $M T A T P 6^{2-4}$ or rarely in $M T A T P 8^{5}$ genes. Their clinical presentation ranges from mild 
disorders to NARP or Leigh syndrome (symmetrical necrotic lesions in basal ganglia and/or the brain stem) and typically depends on the level of mtDNA heteroplasmy. The first ATP synthase deficiency of nuclear genetic origin was described by our group in $1999 .{ }^{6}$ Since then an increasing number of children with ATP synthase deficiency have revealed a similar phenotype with early neonatal onset of hypotonia, hypertrophic cardiomyopathy (HCMP), lactic acidosis and 3-methylglutaconic aciduria (3-MGC-uria). ${ }^{7}$ In 2004, the first pathogenic mutation in the nuclear encoded gene ATP12 was identified ${ }^{9}$ in a patient with dysmorphic features and cortical atrophy. In 2008, we identified for the first time in 23 ATP synthase-deficient patients mutation c.317-2A $\rightarrow \mathrm{G}$ in the TMEM70 gene. ${ }^{10}$ Furthermore, we have proved that TMEM70 is indispensable for ATP synthase biogenesis. Recently, three other children from one family with the same TMEM70 mutation have been described, ${ }^{11}$ thus demonstrating unexpectedly high incidence of this genetic disorder that appears to be the most frequent cause of mitochondrial diseases due to diminished biosynthesis of ATP synthase.

The aim of our study is detailed retrospective characterisation of the phenotype in a genetically homogeneous group of 25 patients with c.317-2A $\rightarrow \mathrm{G}$ mutation in the TMEM70 gene with respect to the natural course of the disease and the longterm prognosis. As we wished to describe frequent symptoms of TMEM70 patients and metabolic profiles, specific attention was paid to the co-occurrence of hypospadia, hyperammonaemia, lactic acidosis and 3-MGC-uria.

\section{PATIENTS AND METHODS \\ Patients}

Twenty five children from seven European countries (14 boys, 11 girls) with ATP synthase deficiency due to TMEM70 mutations were included. Twenty four patients were homozygous for the c.317-2A $\rightarrow \mathrm{G}$ mutation in the TMEM70 gene and one patient (P23) was compound heterozygote c.[317$2 \mathrm{~A} \rightarrow \mathrm{G}]+\left[118 \_119\right.$ insGT] ${ }^{10}$ Twenty four patients from 21 families were of Roma ethnic origin. Three families (F1, F14, F17) were consanguineous. Patient P23 was from a non-consanguineous non-Roma family. A diagnosis of ATP synthase deficiency (activity $<30 \%$ of controls) with pronounced reduction of the ATP synthase content was made by measuring the activity of OXPHOS complexes and by BN-PAGE. Furthermore, mildly decreased activity of complex I (80-90\% of controls) was observed in 10 out of 16 available muscle samples. To provide a complete overview of the phenotype, data from 10 patients reported earlier as indicated in table 1 have been included and updated.

\section{Ethics}

The study was approved by the Committees of Medical Ethics at all collaborating institutions. Informed consent was obtained from parents.

\section{RESULTS}

\section{Natural course of the disease}

The age of onset, the clinical symptoms and the course of the disease in the 25 patients are summarised in table 1. Overall, $68 \%$ of patients were delivered prematurely and intrauterine growth retardation (IUGR) was present in $58 \%$. The mean \pm SD birth weight was $2040 \pm 471$ g (range 1150-3080 g) and mean \pm SD gestation age was $36 \pm 2.6$ weeks (range $31-41$ weeks).
In the majority of patients (92\%), muscular hypotonia, apnoic spells and acute metabolic distress characterised by lactic acidosis and hyperammonaemia (86\%) were present from birth. Artificial ventilation was necessary in 19 neonates. Only in two children (P16, P24) was the onset of disease delayed until 1-3 months of age. Ten patients died during the first episode of metabolic disturbance within the first 6 weeks of life. Six others died later between 14 months and 4.5 years of age following metabolic deterioration as a result of acute respiratory infection or gastroenteritis. Interestingly, one of a pair of monochorionic-monoamniotic twins (P9) died during the neonatal period whereas the other twin (P10) is alive at the age of 8 years. Nine patients are alive, the oldest one being 13 years old. Failure to thrive and growth retardation (below the third percentile) were present in all patients surviving the neonatal period. Microcephaly was documented in $59 \%$ of all patients. Mild cranio-facial dysmorphy with low set ears, a prominent nasal bridge and retrognathia were apparent in 16/24 patients. In P23 (compound heterozygote), apart from the early neonatal onset similar to the other patients, the course of the disease was much milder allowing almost normal psychomotor development with attendance at a regular school.

\section{Central nervous system}

Progressive central nervous impairment was observed in most of the patients surviving the neonatal period (table 1), but the type and severity of neurological symptoms differed. Muscular hypotonia persisted and psychomotor delay developed in most of the children. Overall visual acuity was normal in all children. Neuroimaging was normal in P15, P16, P18, P21 and P24, mild cerebellar hypoplasia was observed in P10 and periventricular cysts in $\mathrm{P} 20$.

\section{Heart and liver}

HCMP was found in $76 \%$ of the patients within the first days of life. In most patients, cardiomyopathy was non-progressive. During follow-up, a marked regression (P19, P20) or even complete disappearance of HCMP (P15, P10, P23) was observed. In three patients (P1, P10, P20), Wolf-Parkinson-White syndrome was present. Hepatomegaly due to cardiac-induced liver congestion developed in $58 \%$ of children during metabolic crises in the first days of life. In patients surviving beyond the neonatal period, neither hepatopathy nor hepatomegaly were present.

\section{Urogenital tract}

In more than half of the boys, coronal or penile hypospadia (54\%) and cryptorchidism (67\%) were present. In at least four families (F7, F9, F10, F14), the hypospadias/cryptorchidism does not occur in other family members and was present only in the probands. Additionally, one third of the patients had inguinal and/or scrotal hernia, which might be the result of prematurity. Renal investigation was performed in five patients (P12, P14-16, P18), in all of whom an ultrasound revealed marked hyperechogenity of renal parenchyma with poor corticomedullar distinction clearly visible at the age of 6-7 weeks. Generalised hyperaminoaciduria (P12, P14, P18) and mild proximal renal tubular acidosis (P12, P18) were present. Glomerular or tubular proteinuria was not documented.

\section{Laboratory data}

After birth, the initial metabolic disturbance was characterised by extreme lactic acidosis (lactate $16 \pm 8 \mathrm{mmol} / \mathrm{l}$, range 5-36 
Table 1 Main clinical symptoms in 25 patients with TMEM70 mutation

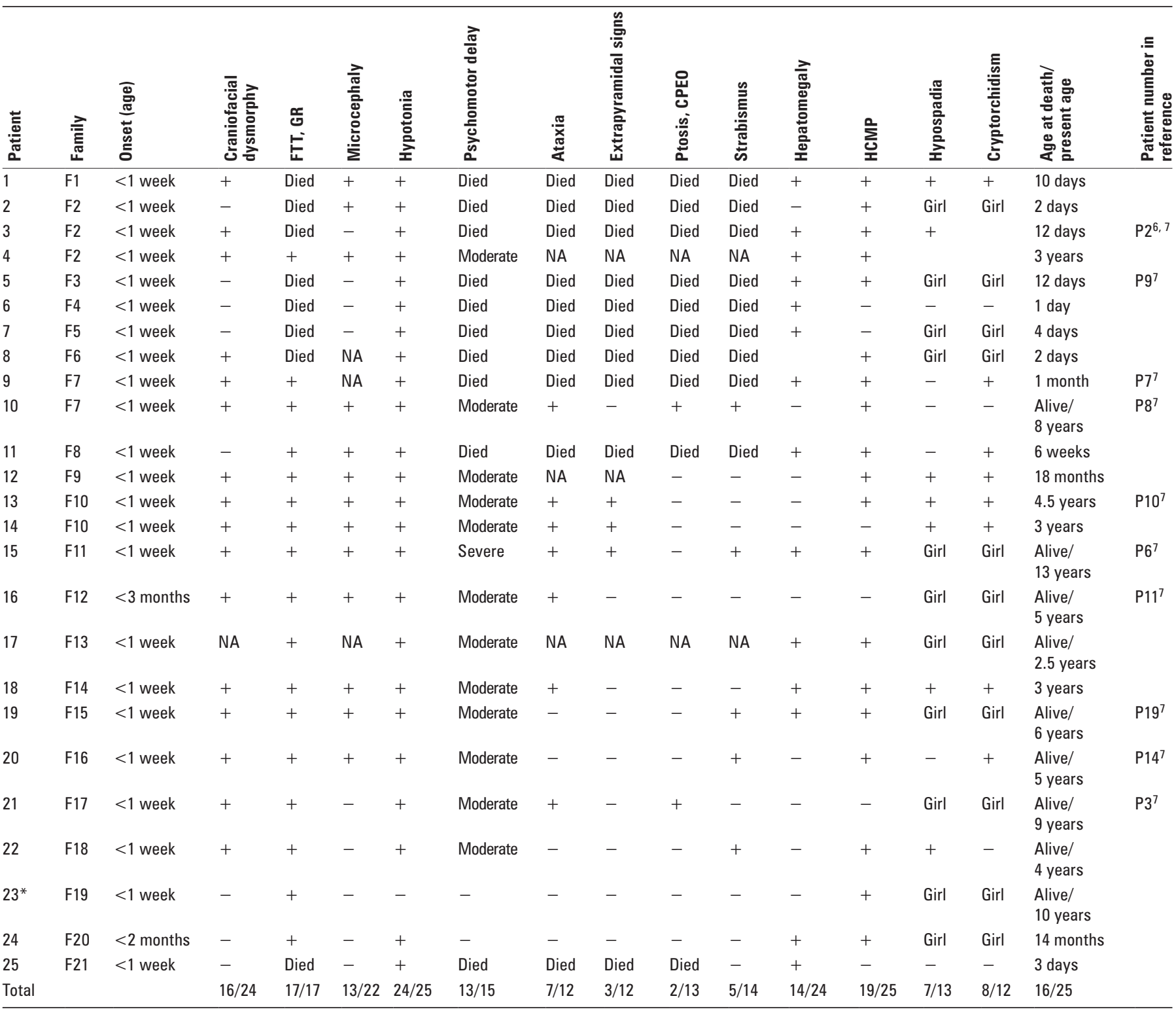

CPEO, chronic progressive external ophthalmoplegia; Died, died too early for evaluation of the symptom; FTT, failure to thrive; GR, growth retardation; HCMP, hypertrophic cardiomyopathy; NA, data not available.

*P23 was compound heterozygote for mutations c.317-2A $\rightarrow$ G/c.118_119insGT in TMEM70.

$\mathrm{mmol} / 1$, controls $<2.3 \mathrm{mmol} / \mathrm{l}$; base excess -6 to $-30 \mathrm{mmol} / \mathrm{l}$ ). Patients surviving 6 weeks presented with intermittent hyperlactacidaemia $(1.6-22.9 \mathrm{mmol} / \mathrm{l})$. Serum alanine was increased in $88 \%(520-3938 \mu \mathrm{mol} / 1$, controls $<500)$ and uric acid in $92 \%$ (420-703 $\mu \mathrm{mol} / 1$, controls <340) of examined cases. Creatine kinase was increased intermittently $(1-30 \mu \mathrm{kat} / 1$, controls $<2.8)$ in 12 out of 14 investigated children.

Altogether, 92 values of lactate measured spectrophotometrically and 77 urinary organic acid profiles determined by gas chromatography-mass spectrometry were available (1-10 from each patient). In all patients, intermittently increased excretion of lactate $(13-68846 \mathrm{mmol} / \mathrm{mol}$ creatinine, controls $<60 ; 36 \%$ of samples within control range) and 3-MGC $(<15-460 \mathrm{mg} / \mathrm{g}$ creatinine, controls $<15 ; 9 \%$ of samples within control range) were observed. 3-Methylglutaric acid (22-361 $\mathrm{mg} / \mathrm{g}$ creatinine, controls $<15$ ) and Krebs cycle intermediates were raised in $70 \%$ of the profiles. In most patients, normal or only mild elevation of urinary excretion of orotic acid was found $(1.7-8.8 \mathrm{mmol} / \mathrm{mol}$ creatinine, controls $<3.5)$.

\section{Hyperammonaemic crises}

In 12 out of 14 children, hyperammonaemia (100-520 $\mu \mathrm{mol} / \mathrm{l}$, controls $<80$ ) was present during acute metabolic disturbance after birth. Six of these children died. In patients P10, P14, P16 and P18, hyperammonaemia (226-870 $\mu \mathrm{mol} / \mathrm{l}$, neonatal controls $<80$ ) occurred during childhood triggered by acute gastroenteritis with prolonged fasting. At the time of admission to the metabolic unit, all four children were sleepy and apathetic, and in one child artificial ventilation was necessary. Liver function tests as well as acylcarnitine profiles were normal. Table 2 summarises the laboratory data of these patients at admission and compares these with data obtained during regular checkups in the outpatient clinic. Except for pronounced ketonuria, urinary excretion of the organic acids including 3-MGC was not altered during acute crisis. In patients P14 and P18, the hyperammonaemia progressed further, and despite therapeutic efforts, these children died.

Low glucose tolerance $(\max 3-4 \mathrm{mg} / \mathrm{kg} / \mathrm{min})$ and further aggravation of hyperlactacidaemia was observed. Fat emulsion 
Table 2 A comparison of biochemical data from four patients obtained during regular check-up in an outpatient clinic and during hyperammonaemic episodes at the time of admission to the metabolic unit

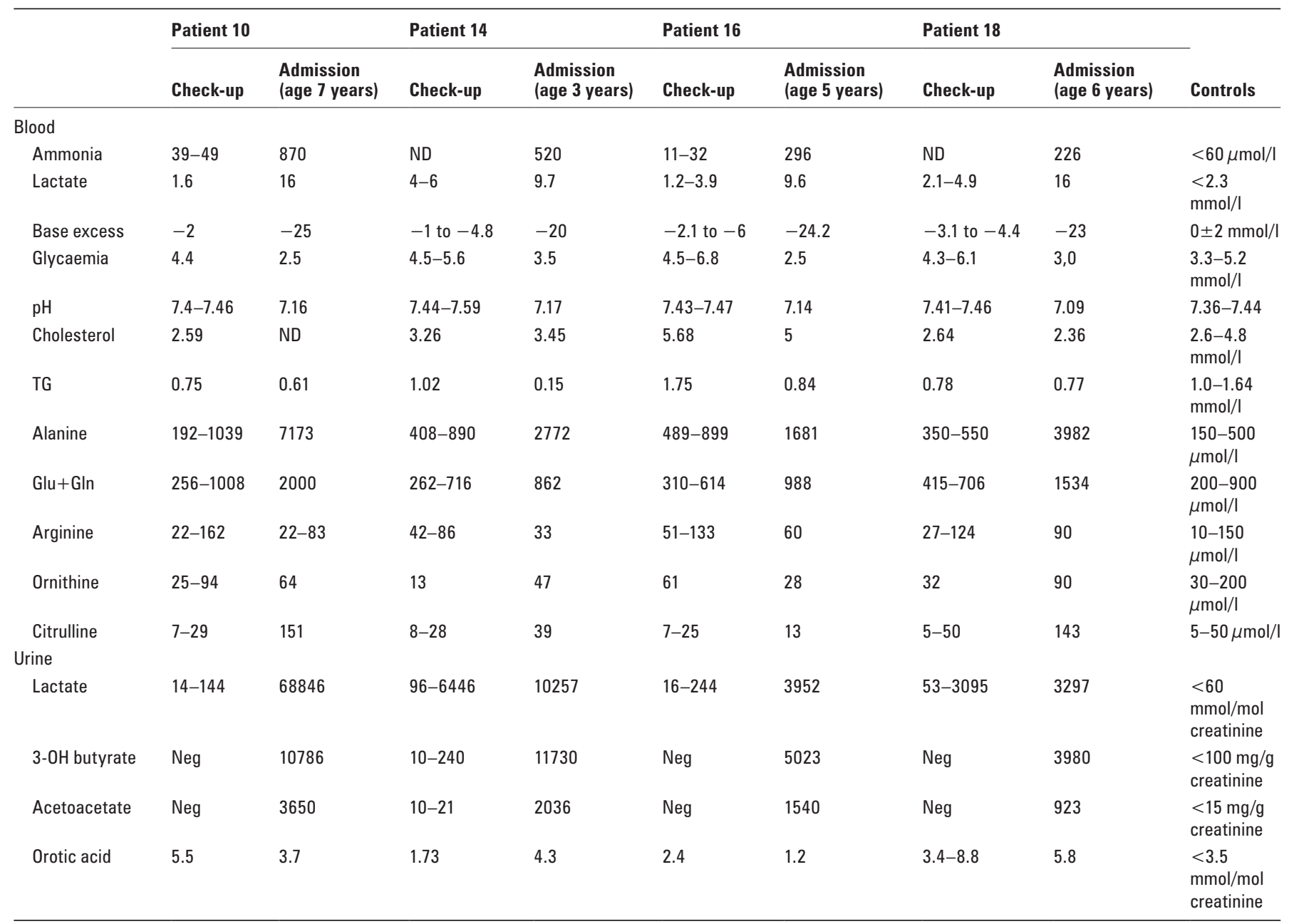

Gln, glutamine; Glu, glutamate; ND, not determined; Neg, negative; TG, triglycerides.

tolerance was preserved enabling lipid supplementation ( $3.5 \mathrm{~g} /$ $\mathrm{kg} /$ day) in all patients with gastroenteritis.

\section{DISCUSSION}

Our study presents for the first time a detailed retrospective analysis of the phenotype and metabolic profiles in a genetically homogenous group of 25 patients with mutations in the TMEM70 gene, coding for a novel factor of ATP synthase biogenesis. The TMEM70 mutation c.317-2A $\rightarrow \mathrm{G}$, found in all patients, leads to aberrant splicing and loss of the TMEM70 transcript. ${ }^{10}$ In the compound heterozygote patient (P23), the frame-shift mutation c.118_119insGT identified on the second allele results in a truncated TMEM70 protein Ser40CysfsX11.

TMEM70 deficiency is characterised by early neonatal onset of hypotonia, HCMP and apnoic spells within hours after birth accompanied by lactic acidosis, hyperammonaemia and 3-MGC-uria. Ten patients died within the first 6 weeks of life and six others died during the toddler and preschool period. Since there were no differences regarding age of onset and severity of clinical symptoms among our patients, one might conclude that management in the intensive care unit is crucial for survival beyond the neonatal period. However, the extremely different survival outcomes of the monochorionicmonoamniotic twins might also indicate the influence of other factors. Early onset is a common feature of other nuclearly encoded defects of mitochondrial ATP synthasome $e^{91213}$ and other OXPHOS deficiencies. ${ }^{14}$ Nevertheless, early neonatal onset with distinctive symptoms and biochemical profiles seems to be crucial for the diagnosis of TMEM70 deficiency. Furthermore, molecular-genetic analysis of the TMEM70 gene is sufficient for diagnosis and analysis of the activity and amount of ATP synthase in biopsy samples can be restricted to TMEM70-negative cases.

In patients surviving 6 weeks, the principle clinical symptoms were functional impairment of the brain, muscle and heart. However, the severity of symptoms together with psychomotor delay, failure to thrive and growth retardation may vary significantly. ${ }^{11}$

Although cardiomyopathy is found in other OXPHOS disorders, ${ }^{15-17}$ defects of ATP synthasome ${ }^{12}{ }^{13}$ and Barth syndrome, ${ }^{18} 19$ its onset and severity varies considerably. HCMP was found in $76 \%$ of TMEM70 patients, and similarly to Barth syndrome and PiC deficiency, ${ }^{12} 2021$ it was present since birth. In the surviving TMEM70-deficient patients, the heart impairment has a benign course. In fact, in three of our patients the HCMP disappeared at the age of 8, 10 and 13 years, respectively. Similarly, improvement in cardiac function was described in Barth syndrome patients ${ }^{22}$ and one patient with complex I deficiency. ${ }^{23}$ However, the disappearance of HCMP or stabilisation of cardiac functions might be orchestrated by AMP-activated protein kinase, a key regulator of cellular energy homeostasis. ${ }^{24-27}$ 
Hypospadias and/or cryptorchidism are not normally observed in OXPHOS disorders. Interestingly, these congenital defects were present in more than $50 \%$ of the boys with TMEM70 mutation. The incidence of hypospadias is estimated at 3.8 per 1000 male newborns ${ }^{28}$ and is similar between Caucasians and other ethnic groups. A significant association between hypospadias and IUGR was described, ${ }^{29}$ but in our patients hypospadias and IUGR did not completely overlap. The higher incidence of hypospadia and/or cryptorchidism in the patients studied suggests a possible link with TMEM70 deficiency. TMEM70-deficient cells display increased mitochondrial membrane potential resulting in increased production of reactive oxygen species ${ }^{30}$ that may alter signalling pathways during the complex developmental process of external male genitalia formation.

Besides hyperlactaciduria, 3-MGC-uria is the most constant laboratory finding in patients with TMEM70 mutations, although other organic acids may be also elevated. Nonetheless, repeated analyses of 3-MGC revealed fluctuations in its level. To date, five distinct types of 3-MGC-uria have been defined. ${ }^{31}$ Interestingly, three types of 3-MGC-uria, namely Barth syndrome (type II, mutation in the TAZ gene), Costeff syndrome (type III, mutation in OPA3) and type $\mathrm{V}$ caused by mutations in DNAJC19, and two syndromes of type IV (TMEM70 deficiency, ANT1 deficiency) are caused by defective proteins related to the inner mitochondrial membrane. Moreover, all these syndromes are characterised by cardiomyopathy. Additionally, hypospadias and/or cryptorchidism are present in TMEM70 and DNAJC19 deficiency.

Hyperammonaemia is a frequent finding in TMEM70deficient patients. Life-threatening hyperammonaemia was described only in a small number of patients with OXPHOS disorders and Barth syndrome. ${ }^{20} 21$ In our study, hyperammonaemia was present in 12 children after birth and four patients developed hyperammonaemia again during acute gastroenteritis with prolonged fasting. In the early phase of catabolism due to fasting, there is marked up-regulation of genes for urea cycle enzymes and the capacity for liver ATP synthesis is strongly enhanced. ${ }^{32}$ Apart from its other cellular roles, ATP is crucial for preserving the functional urea cycle as two of its enzymes (carbamoyl-phosphate synthase (CPS1) and argininosuccinate synthase) are ATP dependent.

A reduced tolerance of sugars and good tolerance of fat emulsions were observed. Administration of fats as a main source of energy to avoid catabolism has led to normalisation of critical metabolic acidosis and to a reduction in hyperlactacidaemia. Based on our experience with TMEM70-deficient patients, similarly to other mitochondrial diseases, ${ }^{33}$ optimal nutritional status with frequent feeding to minimise catabolism is essential to prevent a life-threatening metabolic crisis.

Although our patients came from seven European countries, all 24 homozygotes for c.317-2A $\rightarrow$ G in TMEM70 were of Roma/ Gypsy origin. Approximately 10 million Roma living in Europe form an ethnic group with a common origin. ${ }^{34}$ Genotyping data available in some TMEM70-deficient families ${ }^{10}$ suggest that some of the families may be related back to the third to sixth generations. Based on this information and considering that we analysed the majority of patients known and available, it appears that isolated ATP synthase deficiency caused by mutation c.317-2A $\rightarrow \mathrm{G}$ in TMEM70 is a defect occurring frequently due to a founder allele effect in the Roma population. ${ }^{10}$ ${ }^{35}$ However, other TMEM70 mutations probably occur in other ethnic groups, as might be concluded from our patient P23.

\section{CONCLUSION}

We characterised the natural course of the disease together with detailed metabolic profiles in 25 patients with ATP synthase deficiency due to TMEM70 mutation c.317-2A $\rightarrow \mathrm{G}$, which occurs frequently in the Roma population due to a founder allele effect. Early neonatal onset of severe muscular hypotonia, HCMP and hypospadia in boys accompanied by lactic acidosis, hyperammonaemia and 3-MGC-uria characterise the phenotype. Despite being due to the same TMEM70 mutation, the severity of the phenotype may vary significantly. However, TMEM70 deficiency should be considered in the diagnosis and management of critically ill neonates. Early diagnosis of TMEM70 deficiency together with appropriate intensive care and optimal nutrition to prevent catabolism may improve the life expectancy of affected patients.

Funding This study was supported by grants from the Ministry of Health (IGA-NS 9759-4) and Ministry of Education, Youth and Sports of the Czech Republic (1M0520, AV0Z 50110509, MSM 0021620806) and Verein zur Pädiatrischen Forschung und Fortbildung, Salzburg 0eNB Jubiläumsfonds 12568.

\section{Competing interests None.}

Ethics approval The study was approved by the Committees of Medical Ethics at all collaborating institutions.

Provenance and peer review Not commissioned; externally peer reviewed.

Patient consent Parental consent obtained.

\section{REFERENCES}

1. Shoubridge EA. Nuclear genetic defects of oxidative phosphorylation. Hum Mol Genet 2001;10:2277-84.

2. MITOMAP. A Human Mitochondrial Genome Database. http://www.mitomap. org. 2009(accessed Jan 2010).

3. Houstek J, Pícková A, Vojtísková A, et al. Mitochondrial diseases and genetic defects of ATP synthase. Biochim Biophys Acta 2006;1757:1400-5.

4. Jesina $\mathbf{P}$, Tesarová M, Fornusková D, et al. Diminished synthesis of subunit a (ATP6) and altered function of ATP synthase and cytochrome c oxidase due to the mtDNA 2 bp microdeletion of TA at positions 9205 and 9206 . Biochem J 2004;383:561-71.

5. Jonckheere Al, Hogeveen M, Nijtmans LG, et al. A novel mitochondrial ATP8 gene mutation in a patient with apical hypertrophic cardiomyopathy and neuropathy. J Med Genet 2008;45:129-33.

6. Houstek J, Klement P, Floryk D, et al. A novel deficiency of mitochondrial ATPase of nuclear origin. Hum Mol Genet 1999;8:1967-74.

7. Sperl W, Jesina P, Zeman J, et al. Deficiency of mitochondrial ATP synthase of nuclear genetic origin. Neuromuscul Disord 2006;16:821-9.

8. Houstek J, Mrácek T, Vojtísková A, et al. Mitochondrial diseases and ATPase defects of nuclear origin. Biochim Biophys Acta 2004;1658:115-21.

9. De Meirleir L, Seneca S, Lissens W, et al. Respiratory chain complex V deficiency due to a mutation in the assembly gene ATP12. J Med Genet 2004;:41:120-4.

10. Cízková A, Stránecký V, Mayr JA, et al. TMEM70 mutations cause isolated ATP synthase deficiency and neonatal mitochondrial encephalocardiomyopathy. Nat Genet 2008;40:1288-90.

11. Wortmann SB, Rodenburg RJ, Jonckheere A, et al. Biochemical and genetic analysis of 3-methylglutaconic aciduria type IV: a diagnostic strategy. Brain 2009;132:136-46.

12. Mayr JA, Merkel O, Kohlwein SD, et al. Mitochondrial phosphate-carrier deficiency: a novel disorder of oxidative phosphorylation. Am J Hum Genet 2007;80:478-84.

13. Morava E, Sengers R, Ter Laak H, et al. Congenital hypertrophic cardiomyopathy, cataract, mitochondrial myopathy and defective oxidative phosphorylation in two siblings with Sengers-like syndrome. Eur J Pediatr 2004;163:467-71.

14. Gibson K, Halliday JL, Kirby DM, et al. Mitochondrial oxidative phosphorylation disorders presenting in neonates: clinical manifestations and enzymatic and molecular diagnoses. Pediatrics 2008;122:1003-8.

15. Böhm M, Pronicka E, Karczmarewicz E, et al. Retrospective, multicentric study of 180 children with cytochrome $C$ oxidase deficiency. Pediatr Res 2006;59:21-6.

16. Vesela K, Hansikova H, Tesarova M, et al. Clinical, biochemical and molecular analyses of six patients with isolated cytochrome $\mathrm{c}$ oxidase deficiency due to mutations in the SCO2 gene. Acta Paediatr 2004;93:1312-17.

17. Holmgren D, Wåhlander $\mathrm{H}$, Eriksson $\mathrm{BO}$, et al. Cardiomyopathy in children with mitochondrial disease; clinical course and cardiological findings. Eur Heart J 2003;24:280-8. 
18. Barth PG, Valianpour F, Bowen VM, et al. X-linked cardioskeletal myopathy and neutropenia (Barth syndrome): an update. Am J Med Genet $A$

2004;126A:349-54.

19. Marziliano N, Mannarino S, Nespoli L, et al. Barth syndrome associated with compound hemizygosity and heterozygosity of the TAZ and LDB3 genes. Am J Med Genet A 2007;143A:907-15.

20. Donati MA, Malvagia S, Pasquini E, et al. Barth syndrome presenting with acute metabolic decompensation in the neonatal period. J Inherit Metab Dis 2006;29:684.

21. Yen TY, Hwu WL, Chien YH, et al. Acute metabolic decompensation and sudden death in Barth syndrome: report of a family and a literature review. Eur J Pediatr 2008;167:941-4.

22. Christodoulou J, Mclnnes RR, Jay V, et al. Barth syndrome: clinical observations and genetic linkage studies. Am J Med Genet 1994;50:255-64.

23. Yaplito-Lee J, Weintraub R, Jamsen K, et al. Cardiac manifestations in oxidative phosphorylation disorders of childhood. J Pediatr 2007;150:407-11.

24. Long YC, Zierath JR. AMP-activated protein kinase signaling in metabolic regulation. J Clin Invest 2006;116:1776-83

25. Chan AY, Dolinsky VW, Soltys CL, et al. Resveratrol inhibits cardiac hypertrophy via AMP-activated protein kinase and Akt. J Biol Chem 2008;283:24194-201.

26. Chan AY, Soltys CL, Young ME, et al. Activation of AMP-activated protein kinase inhibits protein synthesis associated with hypertrophy in the cardiac myocyte. $J$ Biol Chem 2004:279:32771-9.
27. Gundewar S, Calvert JW, Jha S, et al. Activation of AMP-activated protein kinase by metformin improves left ventricular function and survival in heart failure. Circ Res 2009;104:403-11.

28. Lund L, Engebjerg MC, Pedersen L, et al. Prevalence of hypospadias in Danish boys: a longitudinal study, 1977-2005. Eur Urol 2009;55:1022-6.

29. Hussain N, Chaghtai A, Herndon CD, et al. Hypospadias and early gestation growth restriction in infants. Pediatrics 2002;109:473-8.

30. Mrácek T, Pecina P, Vojtísková A, et al. Two components in pathogenic mechanism of mitochondrial ATPase deficiency: energy deprivation and ROS production. Exp Gerontol 2006;41:683-7.

31. Wendel U, Ogier de Bauluny H. Branched-chain organic acidurias/acidemias. In: Fernandes J, Saudubray J-M, van den Berghe G, et al., eds. Inborn metabolic diseases diagnosis and treatment. Heidelberg: Springer Medizin Verlag, 2006:245-62.

32. Sokolovic M, Sokolovic A, Wehkamp D, et al. The transcriptomic signature of fasting murine liver. BMC Genomics 2008;9:528.

33. Debray FG, Lambert M, Chevalier I, et al. Long-term outcome and clinical spectrum of 73 pediatric patients with mitochondrial diseases. Pediatrics 2007; 119:722-33.

34. Kalaydjieva L, Morar B, Chaix R, et al. A newly discovered founder population: the Roma/Gypsies. Bioessays 2005;27:1084-94.

35. Houstek J, Kmoch S, Zeman J. TMEM70 protein - a novel ancillary factor of mammalian ATP synthase. Biochim Biophys Acta 2009;1787:529-32. 